CLINICAL STUDY

\title{
The combined low-dose dexamethasone suppression corticotropin-releasing hormone test as a tool to rule out Cushing's syndrome
}

\author{
Giuseppe Reimondo ${ }^{1}$, Silvia Bovio ${ }^{1}$, Barbara Allasino ${ }^{1}$, Silvia De Francia ${ }^{2}$, Barbara Zaggia ${ }^{1}$, Ilaria Micossi ${ }^{1}$, \\ Angela Termine $^{1}$, Francesca De Martino ${ }^{2}$, Piero Paccotti ${ }^{1}$, Francesco Di Carlo ${ }^{2}$, Alberto Angeli ${ }^{1}$ and \\ Massimo Terzolo ${ }^{1}$ \\ ${ }^{1}$ Dipartimento di Scienze Cliniche e Biologiche, Medicina Interna I and ${ }^{2}$ Farmacologia, Università di Torino, A.S.O. San Luigi, Regione Gonzole, 10,10043 \\ Orbassano, Italy \\ (Correspondence should be addressed to G Reimondo; Email: giuseppe.reimondo@unito.it)
}

\begin{abstract}
Objective: It remains to be evaluated whether the combined low-dose dexamethasone suppression corticotropin-releasing hormone test (LDDST-CRH test) may add to the diagnostic approach of patients suspected to have Cushing's syndrome (CS). The aim of the present study was to evaluate whether the LDDST-CRH test may have a place in the diagnostic strategy of CS.

Design: Prospective evaluation of a consecutive series of patients with suspected CS from 2004 to 2006. Methods: All the subjects underwent the same screening protocol including $1 \mathrm{mg}$ dexamethasone suppression test, 24-h urinary free cortisol (UFC), and midnight serum cortisol, followed by the LDDST$\mathrm{CRH}$ test whose results were not used to establish a definitive diagnosis. Plasma dexamethasone concentration was measured $2 \mathrm{~h}$ after the last dose of dexamethasone. Patients qualified for CS when at least two screening tests were positive.

Results: Sixteen patients had CS while in the remaining 15 subjects CS was excluded. Even if not statistically significant, the sensitivity and the negative predictive value of the cortisol $15 \mathrm{~min}$ after $\mathrm{CRH}$ were better than the other tests; on the other hand, the test specificity was lower. All of the patients classified as indeterminate were correctly diagnosed by the LDDST-CRH test. Nevertheless, the repeated assessment of the screening tests and the active follow-up gave the same correct results. In all of the patients misclassified by the LDDST-CRH test, the plasma dexamethasone concentrations were in the normal range.

Conclusions: Based on our findings, we suggest that the LDDST-CRH test may still find a place as a ruleout procedure in patients who present with indeterminate results after screening and may be unavailable to repeat testing during follow-up.
\end{abstract}

European Journal of Endocrinology 159 569-576

\section{Introduction}

Recent data suggest that Cushing's syndrome (CS) presenting in a paucisymptomatic or subclinical way is more frequent than previously thought $(1,2)$. It is indeed a common experience in centers with expertise in CS that an increasing number of patients present with a nonspecific clinical phenotype characterized by recent weight gain, elevated blood pressure, and hyperglycemia. These features are components of the metabolic syndrome and are becoming progressively more common in the general population (3). The recognition of CS is complicated by the fact that cortisol excess may be demonstrated in a number of patients with uncontrolled diabetes mellitus $(4,5)$, obesity (6), or hypertension (7) who do not have CS. Such individuals may be included in a heterogeneous group labeled as 'pseudo-Cushing' (pCS) that is increasingly difficult to differentiate from CS.
Different approaches have been developed over the years, but all of them have demonstrated some limitations (8). In 1993, Yanovski and colleagues (9) described for the first time the combined low-dose dexamethasone suppression corticotropin-releasing hormone test (LDDST-CRH test). Yanovski and colleagues attained 100\% sensitivity and specificity in distinguishing CS from pCS by using a cortisol threshold of $1.4 \mu \mathrm{g} / \mathrm{dl}(38 \mathrm{nmol} / \mathrm{l}) 15 \mathrm{~min}$ after CRH administration (9). In 1998, the same authors reported that the LDDST-CRH test also correctly distinguished all subjects with mild Cushing's disease (CD) from healthy volunteers (10). While yielding the same 100\% specificity, the LDDST-CRH test had significantly greater sensitivity and diagnostic accuracy than dexamethasonesuppressed urine 17-hydroxycorticosteroid or urinary free cortisol (UFC) measurements. Intriguingly enough, the difference between the CRH-stimulated and post-dexamethasone cortisol thresholds did not attain statistical 
significance for sensitivity (10). More recently, the LDDST$\mathrm{CRH}$ test has been the subject of active investigation in a number of studies that did not reproduce the excellent results originally obtained by the NIH group.

Martin and colleagues did not confirm the superiority of the LDDST-CRH test in comparison with the standard LDDST (11). They found that either a cortisol threshold of $1.8 \mu \mathrm{g} / \mathrm{dl}(50 \mathrm{nmol} / \mathrm{l})$ after LDDST, that conventionally excludes CS (12), or a 15-min cortisol cut-point of $1.4 \mu \mathrm{g} / \mathrm{dl}(38 \mathrm{nmol} / \mathrm{l})$ after CRH had $100 \%$ sensitivity to differentiate CS from pCS. However, specificity was considerably lower for the LDDST-CRH test $(67 \%)$ compared with LDDST (88\%). However, Martin and colleagues adapted the procedure of the LDDST-CRH test, as originally described by Yanovski, to maintain the final 48-h time point of the standard LDDST and used humanCRH instead of ovine-CRH. Thus, differences in study protocols may have contributed to discrepant results.

Pecori-Giraldi and colleagues (13) confirmed that the diagnostic accuracy of LDDST-CRH test was less brilliant than previously reported, since the test achieved $100 \%$ sensitivity but specificity was only $62 \%$ and appeared to be inferior to the desmopressin test. They noticed an excellent diagnostic effectiveness using the combination of the LDDST as a highly sensitive first-line test with the desmopressin test as a highly specific second-line test; this testing strategy proved to be superior to the LDDSTCRH test used alone (13).

In a very recent paper, Erickson and colleagues (14) reported that the sensitivity of the LDDST-CRH test was $100 \%$ and specificity $76 \%$ using the cut-point originally described by Yanovski (9), whereas the highest diagnostic accuracy was obtained evaluating the adrenocorticotropin (ACTH) levels obtained $15 \mathrm{~min}$ after CRH stimulation. The diagnostic accuracy of the LDDST-CRH test, albeit superior, was not statistically different from that of 24-h UFC or 2-day LDDST (14).

Similarly, Gatta and colleagues (15) have demonstrated in a retrospective multicenter study that the diagnostic accuracy of the LDDST-CRH test in the differential diagnosis between pCS and mild Cushing was not better than that of either LDDST or midnight serum cortisol (MSC) in equivocal cases.

The aim of the present study was to prospectively evaluate in one referral center whether the LDDST-CRH test may have a role in the diagnosis of endogenous hypercortisolism, following the standard protocol previously described by the NIH group (9).

\section{Materials and methods}

\section{Patients}

We evaluated a consecutive series of 31 individuals (23 women and 8 men, median age 42 years, range 17-75 years) enrolled from 2004 to 2006 for possible hypercortisolism. Our center is an academic referral center for pituitary and adrenal diseases and these subjects were addressed by our outpatient service for either a clinical phenotype suggestive of CS (including a combination of some of the following features: obesity, hypertension, hyperglycemia, irregular menses, buffalo hump, plethoric appearance, hirsutism) or hormonal data indicative of cortisol excess, or both. No patient with adrenal incidentaloma was included in this series. None of the patients had liver or kidney disease, or was taking antiepileptic drugs, or oral contraceptive, and none of them was receiving any drug known to affect the hypothalmic pituitary adrenal (HPA) axis. Furthermore, there were no patients with either alcohol abuse or current or previous history of major mood disorders that required psychiatric help.

A definitive diagnosis of CS was made and thereafter surgically confirmed in 16 patients (13 pituitary dependent and 3 adrenal dependent), whereas in 15 subjects CS was excluded by the results of standard screening tests and a follow-up ranging from 12 to 36 months (median 14 months). CD was confirmed by the finding of a pituitary adenoma with positive ACTH staining at pathological examination in nine patients whereas in the remaining four cases, in whom tumor tissue was not available for pathological studies, the diagnosis was confirmed by the occurrence of postoperative adrenal insufficiency. In all cases of adrenaldependent CS the diagnosis was histologically confirmed. The 15 subjects who were excluded to have CS showed an improvement or lack of progression of signs of possible hypercortisolism during follow-up after treatment for the underlying disorder. These patients had the following clinical diagnoses: metabolic syndrome (nine patients) and polycystic ovary syndrome (six patients). The clinical features of the patients with confirmed CS and patients with excluded CS are shown in Table 1. The institutional review board approved the study and all patients provided written informed consent. The study was performed in accordance with the Declaration of Helsinki.

\section{Study protocol}

All the subjects underwent the same screening protocol comprehensive of $1 \mathrm{mg}$ dexamethasone suppression test (DST; dexamethasone was administered orally at $2300 \mathrm{~h}$, and blood samples were collected on the following morning at $0800 \mathrm{~h}$ for determination of plasma cortisol concentration), determination of 24-h UFC in three different occasions, and MSC in a non-sleeping state after $48 \mathrm{~h}$ of admission. All the tests were performed at our center as inpatient procedures. Determination of UFC and $1 \mathrm{mg}$ DST in the patients who were excluded to have CS were repeated after 6-12 months. The results of the endocrine work-up are reported in Table 2.

The LDDST-CRH test was performed as inpatients within 3 months from the completion of the screening protocol in all individuals, but the results of the test 
Table 1 Demographic and clinical characteristics of our patient cohort.

\begin{tabular}{|c|c|c|c|c|c|c|c|c|c|c|c|c|}
\hline No. & Age & Sex & Hirsutism & $\begin{array}{l}\text { Menstrual } \\
\text { irregularity }\end{array}$ & Hypertension & DM/IGT & $\begin{array}{l}\text { Osteo- } \\
\text { porosis }\end{array}$ & $\begin{array}{l}\text { Central } \\
\text { obesity }\end{array}$ & $\begin{array}{l}\text { Purple } \\
\text { striae }\end{array}$ & $\begin{array}{l}\text { Ecchy- } \\
\text { moses }\end{array}$ & $\begin{array}{c}\text { Muscle } \\
\text { weakness }\end{array}$ & Acne \\
\hline \multicolumn{13}{|c|}{ CS excluded } \\
\hline 1 & 66 & W & $Y$ & - & $Y$ & $Y$ & $\mathrm{~N}$ & $Y$ & $\mathrm{~N}$ & $\mathrm{~N}$ & $\mathrm{~N}$ & $\mathrm{~N}$ \\
\hline 2 & 70 & W & $\mathrm{N}$ & - & $Y$ & $Y$ & $\mathrm{~N}$ & $Y$ & $\mathrm{~N}$ & $\mathrm{~N}$ & $Y$ & $\mathrm{~N}$ \\
\hline 3 & 62 & $\mathrm{M}$ & - & - & $Y$ & $\mathrm{~N}$ & $\mathrm{~N}$ & $Y$ & $\mathrm{~N}$ & $\mathrm{~N}$ & $Y$ & $\mathrm{~N}$ \\
\hline 4 & 33 & W & $\mathrm{N}$ & $Y$ & $Y$ & $\mathrm{~N}$ & $\mathrm{~N}$ & $Y$ & $\mathrm{~N}$ & $\mathrm{~N}$ & $\mathrm{~N}$ & $\mathrm{~N}$ \\
\hline 5 & 30 & W & $\mathrm{N}$ & Y & $\mathrm{N}$ & $Y$ & $\mathrm{~N}$ & $Y$ & $\mathrm{~N}$ & $\mathrm{~N}$ & $\mathrm{~N}$ & $\mathrm{~N}$ \\
\hline 6 & 62 & W & $\mathrm{N}$ & - & $Y$ & $Y$ & $Y$ & $Y$ & $\mathrm{~N}$ & $\mathrm{~N}$ & $\mathrm{~N}$ & $\mathrm{~N}$ \\
\hline 7 & 38 & $\mathrm{M}$ & - & - & $Y$ & $\mathrm{~N}$ & $\mathrm{~N}$ & $Y$ & $\mathrm{~N}$ & $\mathrm{~N}$ & $\mathrm{~N}$ & $\mathrm{~N}$ \\
\hline 8 & 26 & W & $Y$ & $Y$ & $\mathrm{~N}$ & $\mathrm{~N}$ & $\mathrm{~N}$ & $Y$ & $Y$ & $\mathrm{~N}$ & $\mathrm{~N}$ & $\mathrm{~N}$ \\
\hline 9 & 68 & $M$ & - & - & $Y$ & $N$ & $Y$ & $Y$ & $\mathrm{~N}$ & $\mathrm{~N}$ & $Y$ & $\mathrm{~N}$ \\
\hline 10 & 32 & W & $Y$ & $Y$ & $\mathrm{~N}$ & $Y$ & $\mathrm{~N}$ & $Y$ & $\mathrm{~N}$ & $\mathrm{~N}$ & $\mathrm{~N}$ & $Y$ \\
\hline 11 & 27 & $\mathrm{M}$ & - & - & $\mathrm{N}$ & $\mathrm{N}$ & $\mathrm{N}$ & $Y$ & $\mathrm{~N}$ & $\mathrm{~N}$ & $\mathrm{~N}$ & $\mathrm{~N}$ \\
\hline 12 & 51 & W & $\mathrm{N}$ & - & $Y$ & $\mathrm{~N}$ & $Y$ & $Y$ & $\mathrm{~N}$ & $\mathrm{~N}$ & $\mathrm{~N}$ & $\mathrm{~N}$ \\
\hline 13 & 18 & W & $Y$ & $Y$ & $\mathrm{~N}$ & $\mathrm{~N}$ & $\mathrm{~N}$ & $Y$ & $Y$ & $\mathrm{~N}$ & $\mathrm{~N}$ & $Y$ \\
\hline 14 & 23 & W & $Y$ & $Y$ & $\mathrm{~N}$ & $Y$ & $\mathrm{~N}$ & $Y$ & $\mathrm{~N}$ & $\mathrm{~N}$ & $\mathrm{~N}$ & $\mathrm{~N}$ \\
\hline 15 & 38 & W & $Y$ & $Y$ & $\mathrm{Y}$ & $Y$ & $\mathrm{~N}$ & $Y$ & $\mathrm{~N}$ & $\mathrm{~N}$ & $\mathrm{~N}$ & $\mathrm{~N}$ \\
\hline \multicolumn{13}{|c|}{ CS confirmed } \\
\hline 16 & 32 & W & $\mathrm{Y}$ & $\mathrm{Y}$ & $\mathrm{Y}$ & $\mathrm{N}$ & $\mathrm{N}$ & $\mathrm{Y}$ & $\mathrm{N}$ & $\mathrm{N}$ & $\mathrm{N}$ & $\mathrm{N}$ \\
\hline 17 & 30 & W & $Y$ & Y & $Y$ & $\mathrm{~N}$ & $\mathrm{~N}$ & Y & $\mathrm{Y}$ & $\mathrm{N}$ & $\mathrm{N}$ & $\mathrm{N}$ \\
\hline 18 & 72 & W & $\mathrm{Y}$ & - & $\mathrm{Y}$ & $\mathrm{N}$ & $\mathrm{N}$ & Y & $\mathrm{N}$ & $\mathrm{N}$ & $\mathrm{Y}$ & $\mathrm{N}$ \\
\hline 19 & 51 & W & $\mathrm{N}$ & $Y$ & $\mathrm{~N}$ & $\mathrm{~N}$ & $\mathrm{~N}$ & $Y$ & $\mathrm{Y}$ & $\mathrm{N}$ & $\mathrm{N}$ & $\mathrm{N}$ \\
\hline 20 & 46 & $\mathrm{M}$ & - & - & $\mathrm{Y}$ & $\mathrm{N}$ & $\mathrm{Y}$ & $\mathrm{N}$ & $\mathrm{N}$ & $\mathrm{N}$ & $\mathrm{N}$ & $\mathrm{N}$ \\
\hline 21 & 75 & W & $\mathrm{Y}$ & - & $\mathrm{Y}$ & $\mathrm{Y}$ & $\mathrm{Y}$ & $\mathrm{Y}$ & $\mathrm{N}$ & $\mathrm{N}$ & $\mathrm{N}$ & $\mathrm{N}$ \\
\hline 22 & 60 & $\mathrm{M}$ & - & - & $Y$ & $\mathrm{Y}$ & $\mathrm{N}$ & $\mathrm{N}$ & $\mathrm{N}$ & $\mathrm{N}$ & $\mathrm{Y}$ & $\mathrm{N}$ \\
\hline 23 & 42 & W & $\mathrm{N}$ & $\mathrm{N}$ & $Y$ & $\mathrm{~N}$ & $\mathrm{Y}$ & $\mathrm{Y}$ & $\mathrm{N}$ & $\mathrm{N}$ & $\mathrm{Y}$ & $\mathrm{N}$ \\
\hline 24 & 43 & W & $\mathrm{N}$ & $Y$ & $\mathrm{~N}$ & $\mathrm{~N}$ & $Y$ & $\mathrm{~N}$ & $\mathrm{~N}$ & $\mathrm{~N}$ & $Y$ & $\mathrm{Y}$ \\
\hline 25 & 42 & W & $\mathrm{Y}$ & $Y$ & $\mathrm{~N}$ & $\mathrm{~N}$ & $Y$ & $\mathrm{Y}$ & $\mathrm{N}$ & $\mathrm{N}$ & $\mathrm{N}$ & $\mathrm{N}$ \\
\hline 26 & 70 & $\mathrm{M}$ & - & - & $\mathrm{Y}$ & $\mathrm{N}$ & $\mathrm{N}$ & $\mathrm{N}$ & $\mathrm{N}$ & $\mathrm{N}$ & $\mathrm{Y}$ & $\mathrm{N}$ \\
\hline 27 & 42 & W & $\mathrm{N}$ & $\mathrm{N}$ & $\mathrm{Y}$ & $\mathrm{Y}$ & $\mathrm{N}$ & $\mathrm{Y}$ & $\mathrm{N}$ & $\mathrm{N}$ & $\mathrm{Y}$ & $\mathrm{N}$ \\
\hline 28 & 55 & $M$ & - & - & $Y$ & $\mathrm{Y}$ & $\mathrm{N}$ & $Y$ & $\mathrm{~N}$ & $\mathrm{~N}$ & $\mathrm{Y}$ & $\mathrm{N}$ \\
\hline 29 & 50 & W & $\mathrm{N}$ & $\mathrm{Y}$ & $Y$ & $\mathrm{~N}$ & $Y$ & $Y$ & $\mathrm{~N}$ & $\mathrm{~N}$ & $\mathrm{~N}$ & $\mathrm{~N}$ \\
\hline 30 & 42 & W & $\mathrm{Y}$ & Y & $\mathrm{N}$ & $\mathrm{N}$ & $Y$ & $\mathrm{~N}$ & $\mathrm{~N}$ & $\mathrm{~N}$ & $\mathrm{~N}$ & $\mathrm{~N}$ \\
\hline 31 & 33 & W & $Y$ & $Y$ & $Y$ & $\mathrm{~N}$ & $\mathrm{~N}$ & $Y$ & $\mathrm{~N}$ & $\mathrm{~N}$ & $\mathrm{~N}$ & $\mathrm{~N}$ \\
\hline
\end{tabular}

M, man; W, woman; $Y$, yes; N, no.

were not used to establish a definitive diagnosis. The outcome of LDDST-CRH was compared with the other screening tests only after unequivocal demonstration or exclusion of CS.

The diagnosis of CS was formulated when at least two of the following criteria were fulfilled: i) elevated UFC, ii) failure to suppress cortisol after $1 \mathrm{mg}$ DST, iii) elevated MSC concentration (16). Normal values were set at UFC concentrations of $238 \mu \mathrm{g} / 24 \mathrm{~h}(657 \mathrm{nmol} / 24 \mathrm{~h})$ or less, at post-DST cortisol concentrations of $4.0 \mu \mathrm{g} / \mathrm{dl}$ $(110 \mathrm{nmol} / \mathrm{l})$, and at midnight cortisol concentrations of $8.3 \mu \mathrm{g} / \mathrm{dl} \quad(229 \mathrm{nmol} / \mathrm{l})$. These cut-points were previously established in-house (16). Such patients underwent additional work-up that included: ACTH measurement in baseline conditions and after CRH stimulation, overnight $8 \mathrm{mg}$ DST, radiologic imaging (pituitary magnetic resonance imaging (MRI) or adrenal CT depending on ACTH values), and inferior petrosal sinus sampling in conjunction with $\mathrm{CRH}$ stimulation in patients with ACTH-dependent hypercortisolism with negative MRI and/or inconclusive biochemical studies. In six patients with excluded CS, pituitary MRI was performed and in none of them was there any evidence of adenoma.
LDDST-CRH test was carried out as previously described $(9,10)$ : individuals received $0.5 \mathrm{mg}$ dexamethasone orally every $6 \mathrm{~h}$ for eight doses, starting at $1200 \mathrm{~h}$. A blood sample for serum cortisol and plasma dexamethasone concentration was taken $2 \mathrm{~h}$ after the last dose of dexamethasone $(0800 \mathrm{~h})$ and just before administration of i.v. bolus injection of $100 \mu \mathrm{g}$ ovineCRH (Clinalfa, Darmastadt, Germany). Plasma samples were assayed for cortisol at 15, 30, 45, and 60 min after CRH. Criteria to exclude CS were set at cortisol concentration of $1.8 \mu \mathrm{g} / \mathrm{dl}(50 \mathrm{nmol} / \mathrm{l})$ or less after the LDDST (12) and of $1.4 \mu \mathrm{g} / \mathrm{dl}(38 \mathrm{nmol} / \mathrm{l})$ or less $15 \mathrm{~min}$ after CRH injection $(9,10)$.

\section{Hormone assays}

Hormonal variables were measured using commercially available methods purchased by Sorin Biomedica (Saluggia, Italy) for the measurement of serum and urinary cortisol (RIA) and Nichols Institute (San Juan Capistrano, CA, USA) for plasma ACTH (IRMA). All the hormone assays of a given patient were performed in duplicate. Intra- and inter-assay coefficients of variation were: 4.2 and $8.0 \%$ for serum cortisol, 4.3 and $8.7 \%$ for 
Table 2 Results of the endocrine work-up in our patient cohort.

\begin{tabular}{|c|c|c|c|c|c|c|c|}
\hline No. & $\begin{array}{c}\text { 24-h UFC } \\
\text { (n.v. }<238 \mu \mathrm{g} / 24 \text { h) }\end{array}$ & $\begin{array}{l}\text { Repeated } \\
\text { 24-h UFC }\end{array}$ & $\begin{array}{c}1 \text { mg DST } \\
\text { (n.v. }<4 \mu \mathrm{g} / \mathrm{dl})\end{array}$ & $\begin{array}{l}\text { Repeated } \\
1 \mathrm{mg} \text { DST }\end{array}$ & $\begin{array}{c}\text { MSC } \\
\text { (n.v. }<8.3 \mu \mathrm{g} / \mathrm{dl} \text { ) }\end{array}$ & $\begin{array}{l}\text { Cortisol after } \\
\text { LDDST } \\
\text { (n.v. }<1.8 \mu \mathrm{g} / \mathrm{dl} \text { ) }\end{array}$ & $\begin{array}{c}\text { Cortisol at } 15 \text { min } \\
\text { post-CRH } \\
\text { (n.v. }<1.4 \mu \mathrm{g} / \mathrm{dl})\end{array}$ \\
\hline \multicolumn{8}{|c|}{ CS excluded } \\
\hline 1 & 113 & 80 & 1.7 & 1.4 & 5.5 & 1.9 & 1.9 \\
\hline 2 & 188 & 145 & 14.4 & 1.7 & 4.0 & 0.5 & 0.4 \\
\hline 3 & 190 & 140 & 2.7 & 1.8 & 3.2 & 1.3 & 1.3 \\
\hline 4 & 56 & 76 & 1.0 & 1.2 & 1.0 & 0.5 & 0.5 \\
\hline 5 & 57 & 88 & 0.9 & 1.0 & 1.9 & 0.5 & 0.6 \\
\hline 6 & 55 & 75 & 1.5 & 1.4 & 2.0 & 1.2 & 1.1 \\
\hline 7 & 32 & 54 & 1.8 & 1.6 & 1.8 & 1.0 & 1.0 \\
\hline 8 & 115 & 88 & 1.0 & 0.9 & 1.3 & 0.5 & 0.5 \\
\hline 9 & 38 & 65 & 1.2 & 1.4 & 2.6 & 0.3 & 0.2 \\
\hline 10 & 189 & 144 & 1.5 & 1.7 & 5.1 & 1.5 & 1.6 \\
\hline 11 & 238 & 181 & 1.0 & 1.3 & 2.0 & 0.5 & 0.5 \\
\hline 12 & 33 & 74 & 1.0 & 1.5 & 1.0 & 0.9 & 0.9 \\
\hline 13 & 150 & 197 & 1.0 & 1.2 & 4.2 & 0.7 & 0.5 \\
\hline 14 & 40 & 54 & 1.2 & 1.0 & 0.9 & 1.2 & 1.5 \\
\hline 15 & 233 & 93 & 3.4 & 0.7 & 8.3 & 0.5 & 0.5 \\
\hline \multicolumn{8}{|c|}{ CS confirmed } \\
\hline 16 & 1026 & & 19.5 & & 12.0 & 19.0 & 18.9 \\
\hline 17 & 1130 & & 7.7 & & 6.7 & 8.9 & 19.0 \\
\hline 18 & 160 & 280 & 4.2 & 5.6 & 6.0 & 4.2 & 13.8 \\
\hline 19 & 200 & & 11.8 & & 8.5 & 13.4 & 13.5 \\
\hline 20 & 848 & & 4.1 & & 6.1 & 2.7 & 6.5 \\
\hline 21 & 840 & & 6.7 & & 25.0 & 1.4 & 3.0 \\
\hline 22 & 508 & 420 & 2.5 & 6.0 & 6.1 & 2.6 & 2.3 \\
\hline 23 & 1019 & & 25.0 & & 17.4 & 21.2 & 19.3 \\
\hline 24 & 250 & & 10.0 & & 13.4 & 23.0 & 33.0 \\
\hline 25 & 201 & 312 & 1.6 & 2.7 & 10.4 & 4.3 & 3.8 \\
\hline 26 & 737 & & 28.8 & & 7.5 & 6.1 & 7.6 \\
\hline 27 & 1450 & & 25.0 & & 18.3 & 22.0 & 20.0 \\
\hline 28 & 449 & & 23.0 & & 13.7 & 2.1 & 1.8 \\
\hline 29 & 363 & & 9.6 & & 3.9 & 1.2 & 1.1 \\
\hline 30 & 200 & & 8.0 & & 10.4 & 4.7 & 14.0 \\
\hline 31 & 276 & & 14.4 & & 7.7 & 1.2 & 1.7 \\
\hline
\end{tabular}

To convert conventional units to SI units: for cortisol, multiply by 27.59 to obtain nanomoles per liter; for UFC, multiply by 2.759 to obtain nanomoles per $24 \mathrm{~h}$. ${ }^{a}$ Median of three determinations.

ACTH, and 5.2 and $9.4 \%$ for UFC. Sensitivity of the methods was $0.2 \mu \mathrm{g} / \mathrm{dl}(5.5 \mathrm{nmol} / \mathrm{l})$ for cortisol assay and $4.5 \mathrm{pg} / \mathrm{ml}(1 \mathrm{pmol} / \mathrm{l})$ for ACTH.

The concentration of dexamethasone in plasma was measured by a high pressure liquid chromatography (HPLC) method run on a Merk-Hitachi system (Lachrom 7000). Briefly, plasma samples were deproteinized with $\mathrm{CH} 3 \mathrm{CN}$, then a solid phase extraction clean up on a $\mathrm{C} 18$ reversed-phase column was performed to obtain an extracted fraction suitable for HPLC-UV analysis. The limit of detection in plasma was $0.02 \mu \mathrm{g} / \mathrm{ml}(0.05 \mu \mathrm{mol} / \mathrm{l})$. Standard stock solutions were prepared by dissolving in ethanol $1 \mathrm{mg} / \mathrm{ml}$ commercial preparations of dexamethasone and methylprednisolone (used as internal standards). All solutions were stable for up to 3 months when stored at $-20^{\circ} \mathrm{C}$. The solid phase extraction (SPE) columns $(100 \mathrm{mg} / 1.5 \mathrm{ml})$ were used for sample extraction and the HPLC system was used to separate and quantify the steroids. The chromatographic equipment consisted of UV detector (L-7400), column oven (L-7300), auto sampler (L-7200), and pump (L-7100). System management and data acquisition were performed with the
HSM software (Fortuna Power System Ltd, Hampshire, England). Separation was achieved with a $\mathrm{C} 18$ reversedphase column (Lichrocart 250-4 Lichrospher 100 RP$18.5 \mu \mathrm{m})$ preceded by a guard column. Each sample or calibration sample $(1.5 \mathrm{ml})$, spiked with $12.5 \mu \mathrm{l}$ of $50 \mu \mathrm{g} / \mathrm{ml}$ of internal standard solution, was applied to a SPE column, which was previously equilibrated with $1 \mathrm{ml}$ of methanol followed by $1 \mathrm{ml}$ of water. After sample injection in SPE, the washing steps were: $1 \mathrm{ml}$ of water followed by $2 \mathrm{ml}$ of acetone-water solution (1/4, $\mathrm{v} / \mathrm{v}$ ) and $1 \mathrm{ml}$ of hexane. Afterward, $1 \mathrm{ml}$ of diethyl ether was added and the elute was completely desiccated. Each dried sample was then resuspended with $200 \mu \mathrm{l}$ of mobile phase. Chromatography separation was carried out by isocratic elution with methanol-water $(61 / 39, \mathrm{v} / \mathrm{v})$ at $35^{\circ} \mathrm{C}$ and the process of each chromatographic analysis ended in $10 \mathrm{~min}$. The mobile phase flow rate was $0.9 \mathrm{ml} / \mathrm{min}$. The sample injection volume was $80 \mu \mathrm{l}$. The HSM software integration was employed for dexamethasone quantitative analysis measuring the absorbance at $254 \mathrm{~nm}$ wavelengths. Quantification of dexamethasone was 
performed by internal standard curve calibration (range: $0.078 / 10 \mu \mathrm{g} / \mathrm{ml}(0.22 / 27.7 \mu \mathrm{mol} / \mathrm{l})$ ). Retention time of dexamethasone peak was $7.6 \mathrm{~min}$.

\section{Statistical analysis}

Sensitivity, specificity, positive, and negative predictive values of cortisol levels at the end of the LDDST, before CRH stimulation, and at 15-min post-CRH were calculated using standard methods. Univariate curves of the receiver operating characteristics (ROC) were calculated to define the best cut-off values with relevant sensitivity and specificity for each test. The point on a ROC curve closest to sensitivity of $100 \%$ and 1 - specificity of $0 \%$ provides the best cut-off value, or the test efficiency. The area under each ROC curve was calculated and a comparison between the areas was performed. Values for the area can be between 0 and 1 ; a value of 0.5 means that the diagnostic test is no better than chance. Rates and proportions were calculated for categorical data and means and S.D. for continuous data; 95\% confidence intervals (CI) have always been provided. For continuous variables, differences were analyzed by means of the two-tailed Student's $t$-test when data were normally distributed and by using the Mann-Whitney $U$ test for nonparametric data. For categorical variables, differences were analyzed by means of the $\chi^{2}$ test with Yates correction. Levels of statistical significance were set at $P<0.05$. All analyses were performed using the Statistica software package (Microsoft Corp.) with the exception of the ROC curves, which were constructed using the MedCalc software package (MedCalc Software, Mariakerke, Belgium).

\section{Results}

Two patients who were finally considered to not have CS had UFC at the upper limit of normalcy (patients \#11 and 15) and one of them had a concomitant midnight cortisol at the upper limit of normalcy (patient \#15). Another patient had elevated post-DST cortisol (patient \#2). Repeat assessments of UFC and $1 \mathrm{mg}$ DST during follow-up were normal in such patients. In particular, patient \#15 is still on active follow-up demonstrating important weight loss, amelioration of metabolic parameters, and restoration of normal menstrual pattern with life-style changes and metformin treatment. Conversely, three patients with confirmed CS had equivocal screening results (patients \#18, 22, and 25; Table 2). These data were considered as indeterminate and the patients were submitted to repeat assessment of UFC and DST within 3 months. The reevaluation demonstrated either in patient \#18 or in patient \#22 elevated UFC and non-suppression after DST and in patient \#25 elevated UFC while post-DST cortisol was confirmed suppressed (Table 2).

All the subjects who were screened for CS completed the LDDST-CRH test independently of final exclusion or confirmation of the diagnosis. At the end of the LDDST and before CRH stimulation, three patients with confirmed CS (patients \#21, 29, and 31) had cortisol levels lower than $1.8 \mu \mathrm{g} / \mathrm{dl}(50 \mathrm{nmol} / \mathrm{l})$ and one subject (patient \#1) with excluded CS had cortisol levels above the cut-point (Fig. 1, Table 2). Cortisol levels at 15-min post-CRH, were lower than $1.4 \mu \mathrm{g} / \mathrm{dl}(38 \mathrm{nmol} / \mathrm{l})$ in one patient with confirmed CS (patient \#29) and higher in three subjects with excluded CS (patients \#1, 10, and 14; Fig. 1, Table 2). Sensitivity, specificity, positive, and negative predictive values of the LDDSTCRH test compared with the other screening tests did not significantly differ (Table 3 ). In our series, ROC analysis defined that the best cut-off value for cortisol levels after LDDST and before CRH injection was $1.9 \mu \mathrm{g} / \mathrm{dl} \quad(52 \mathrm{nmol} / \mathrm{l}$; sensitivity, $81.2 \% \quad(95 \% \quad \mathrm{CI}$, $54.3-95.7 \%)$, specificity $100 \%$, (95\% CI, $78.0-$ $100 \%)$ ), while the best cut-off value for cortisol levels at $15-\mathrm{min}$ post-CRH was $1.6 \mu \mathrm{g} / \mathrm{dl}(44 \mathrm{nmol} / \mathrm{l}$; sensitivity $93.7 \%$ (95\% CI, 69.7-99.0\%), specificity $93.3 \%$ (95\% CI, 68.0-98.9\%)). ROC curves were also created to establish cut-off values of post-CRH cortisol concentrations at each time point but none attained higher diagnostic accuracy. When adopting the optimal thresholds established in our series by the ROC curves, the area under the ROC curve of cortisol after LDDST and of $15 \mathrm{~min}$ cortisol post-CRH were not statistically different from those of the other screening tests $(1 \mathrm{mg}$

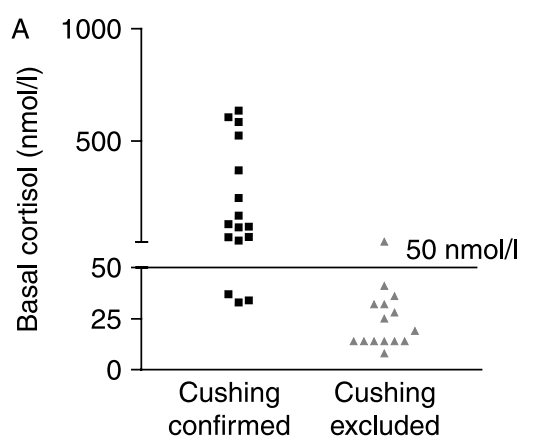

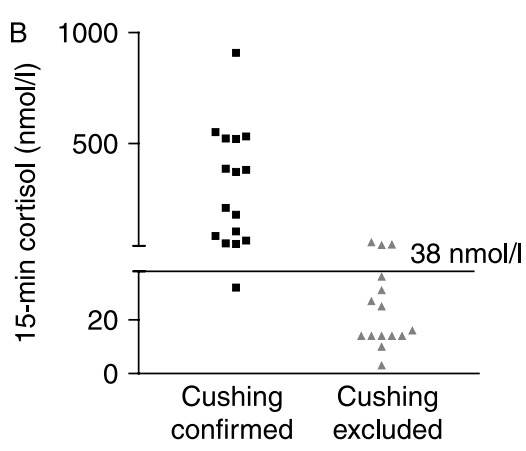

Figure 1 Individual data showing plasma cortisol levels in patients with confirmed Cushing (black square) and excluded Cushing (grey triangle); (A) basal plasma cortisol after LDDST and (B) plasma cortisol obtained 15 min after CRH stimulation. 
Table 3 Diagnostic performance of the different screening tests.

\begin{tabular}{lcccc}
\hline & Sensitivity & Specificity & PPV & NPV \\
\hline LDDST & $81.2(53.6-95.0)$ & $93.3(66.0-99.6)$ & $92.8(64.1-99.6)$ & $82.3(55.8-95.3)$ \\
15 min after CRH & $93.7(67.7-99.6)$ & $80.0(51.3-94.7)$ & $83.3(57.7-95.6)$ & $92.3(62.1-99.6)$ \\
UFC & $75.0(47.4-91.6)$ & $100(74.6-100)$ & $100(69.8-100)$ & $78.9(53.9-93.0)$ \\
MSC & $56.2(30.5-79.2)$ & $100(74.6-100)$ & $100(62.8-100)$ & $68.2(45.1-85.3)$ \\
1 mg DST & $87.5(60.4-97.8)$ & $93.3(66.0-99.6)$ & $93.3(66.0-99.6)$ & $87.5(60.4-97.8)$ \\
\hline
\end{tabular}

PPV, positive predictive value; NPV, negative predictive value. Data are expressed as percent and $95 \%$ confidence interval.

DST, 24-h UFC, and MSC; Fig. 2). The patients with equivocal results at the first screening were correctly categorized by the LDDST-CRH test, as was the case for repeat work-up with the standard tests.

In the whole series, plasma dexamethasone concentrations ranged between 0.02 and $0.087 \mu \mathrm{g} / \mathrm{ml}$ and we have not observed any significant difference between patients with confirmed or excluded diagnosis of CS $(0.044 \pm 0.016 \mu \mathrm{g} / \mathrm{ml}(0.12 \pm 0.04 \mu \mathrm{mol} / \mathrm{l})$ vs $0.047 \pm$ $0.019 \mu \mathrm{g} / \mathrm{ml}(0.13 \pm 0.05 \mu \mathrm{mol} / \mathrm{l}), P=\mathrm{NS})$. A group of ten healthy subjects, who underwent the same protocol of dexamethasone administration, served as controls and the plasma dexamethasone concentrations ranged between 0.03 and $0.07 \mu \mathrm{g} / \mathrm{ml}$. All of the patients incorrectly diagnosed by the LDDST-CRH either at baseline or 15-min after CRH had plasma dexamethasone concentrations in the normal range.

\section{Discussion}

After the demonstration by Yanovski and colleagues that the use of CRH stimulation after the standard LDDST was able to differentiate all cases of CS from pCS (9), as well as mild CD from healthy subjects (10), with $100 \%$ specificity, sensitivity, and diagnostic accuracy, the LDDST-CRH test gained the reputation of a highly reliable diagnostic tool. The test was included in the diagnostic algorithm of endogenous hypercortisolism as a second-line procedure because it was considered to be costly and cumbersome and in need of confirmation by other centers $(8,17)$. In the last 2 years, four reports $(11,13-15)$ have assessed the diagnostic value of the LDDST-CRH test and failed to confirm a sensitivity and specificity close to $100 \%$. Moreover, these authors found that the LDDST-CRH test had a lower $(11,13,15)$, or at the very best comparable (14), diagnostic accuracy compared with the other screening tests. Very recently, Nieman has addressed the issue of the discrepancy between the original experience at the NIH and the more recent studies at other centers and pointed out in her comment that several factors may have contributed to the observed difference, although it is not uncommon for diagnostic accuracy to decrease as tests move from controlled research settings to clinics (18). It is pertinent to this discussion that the thresholds attaining the best operative characteristics are in the lower range of the assay functional detection curve, thus analytical variability may represent an important confounding factor whenever cortisol measurement is not performed in research laboratories.

The present study confirms and extends the recent demonstrations that the LDDST-CRH test should not be included in the standard approach to a patient with suspected CS. We have adopted the original cut-point of $1.4 \mu \mathrm{g} / \mathrm{dl}(38 \mathrm{nmol} / \mathrm{l})$ for cortisol $15 \mathrm{~min}$ after CRH as proposed by Yanovski (9) and found that its diagnostic accuracy was not significantly different from the other screening tests, included the evaluation of cortisol after the LDDST preceding CRH stimulation. However, sensitivity of the cortisol 15 min after CRH was higher than the other tests, even if levels of statistical significance were not attained due to the limited number of patients; on the other hand, the test specificity was lower. Although not statistically significant, the LDDST-CRH test has a greater negative predictive value and might be considered the best test to rule out the patients suspected to have endogenous hypercortisolism. We recognize the limit of the small sample size of our study that may influence the estimate of the diagnostic performance of the different tests.

In many patients in our series, recognition of endogenous cortisol excess was challenging and this may explain why the LDDST-CRH test showed worse results compared with previous series $(11,13-15)$. The presence of six patients ( $19 \%$ of the whole series) who presented equivocal results of the screening tests confirms the diagnostic complexity of our series, which is well reproducing the modern-day presentation

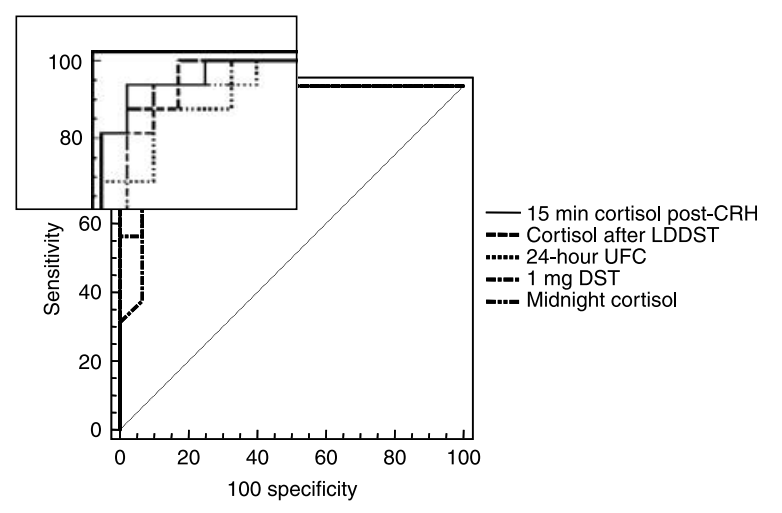

Figure 2 Comparison between the ROC curves. 
of CS characterized by subtler physical signs and biochemical alterations than in the past (2). Interestingly, all of the patients classified as indeterminate were correctly diagnosed by the LDDST-CRH test. Nevertheless, the repeated assessment of the screening tests and the active follow-up gave the same correct results. Also the population studied by Erickson and colleagues was formed by patients with mild CS even if they restricted evaluation to subjects with CD (14); thus, their results may be less generalizable, and indeed most patients with a mild phenotype have adrenal-dependent CS $(2,19)$.

Strengths of the present study are its prospective and monocentric nature, application of the original $\mathrm{NIH}$ protocol for the LDDST-CRH test, measurement of plasma dexamethasone concentrations, and the fact that the results of the test under investigation were not used to establish the diagnosis, that is to say to define the status of patient or control in the evaluated series. In our series, patients qualified for CS after application of a screening protocol that was previously validated in our center (16). Since the characteristics of the assays are variable across different laboratories and also the clinical features of patients suspected to have Cushing may vary depending on characteristics of the local population, referral patterns of the centers, and other variables, we have compared the diagnostic performance of the LDDST-CRH test with the best cutpoints of the standard screening tests, as they were determined in-house. Noticeably, the cut-points used at our center and their relative performance may not be fully generalized; in particular, we recognize that our UFC assay has a lower specificity than HPLC methods. With the exception of the original paper, none of the previous studies have provided data on plasma dexamethasone levels. In the present study, we have measured plasma dexamethasone levels, which were in the normal range also in the patients who were misdiagnosed by the LDDST-CRH test. Thus, we can reasonably exclude the presence of confounding due to different procedures of the LDDST-CRH test or variable dexamethasone metabolism.

In summary, the accuracy of the LDDST-CRH test in the diagnostic approach of subjects suspected to have CS was comparable with the other screening tests. However, the complexity and costs of the LDDST-CRH test make it unsuitable as a screening procedure and, on the other hand, the low specificity of the test militates against its routine use as a confirmatory procedure. The LDDST-CRH test may still find a place as a rule-out procedure either in patients who present with persistently indeterminate screening results after reassessment or in subjects who may be unavailable to repeat testing during follow-up. However, prolonged follow-up with repeat assessment may be the preferred option, as it is recommended by the Endocrine Society's clinical guidelines (20).

\section{Declaration of interest}

The authors declare that there is no conflict of interest that would prejudice the impartiality of this scientific work.

\section{Funding}

This work has been supported by a grant of 'Regione Piemonte Ricerca Finalizzata 2007'. The funding source had no role in the collection, analysis, and interpretation of the data or in the decision to submit the results for publication.

\section{References}

1 Catargi B, Rigalleau V, Poussin A, Ronci-Chaix N, Bex V, Vergnot V, Gin H, Roger P \& Tabarin A. Occult Cushing's syndrome in type-2 diabetes. Journal of Clinical Endocrinology and Metabolism $2003 \mathbf{8 8}$ 5808-5813.

2 Findling JW \& Raff H. Screening and diagnosis of Cushing's syndrome. Endocrinology and Metabolism Clinics of North America 200534 385-402.

3 Ford ES. Prevalence of the metabolic syndrome in US populations. Endocrinology and Metabolism Clinics of North America 200433 333-350.

4 Tsigos C, Young RJ \& White A. Diabetic neuropathy is associated with increased activity of the hypothalamic-pituitary-adrenal axis. Journal of Clinical Endocrinology and Metabolism $1993 \mathbf{7 6}$ 554-558.

5 Roy MS, Roy A, Gallucci WT, Collier B, Young K, Kamilaris TC \& Chrousos GP. The ovine corticotrophin-releasing hormone stimulation test in type 1 diabetic patients and controls: suggestion of mild hypercortisolism. Metabolism $1993 \mathbf{4 2} 696-700$.

6 García-Prieto MD, Tébar FJ, Nicolás F, Larqué E, Zamora S \& Garaulet M. Cortisol secretary pattern and glucocorticoid feedback sensitivity in women from a Mediterranean area: relationship with anthropometric characteristics, dietary intake and plasma fatty acid profile. Clinical Endocrinology 200766 185-191.

7 Chamarthi B, Kolatkar NS, Hunt SC, Williams JS, Seely EW, Brown NJ, Murphey LJ, Jeunemaitre X \& Williams GH. Urinary free cortisol: an intermediate phenotype and a potential genetic marker for a salt-resistant subset of essential hypertension. Journal of Clinical Endocrinology and Metabolism 200792 1340-1346.

8 Arnaldi G, Angeli A, Atkinson AB, Bertagna X, Cavagnini F, Chrousos GP, Fava GA, Findling JW, Gaillard RC, Grossman AB, Kola B, Lacroix A, Mancini T, Mantero F, Newell-Price J, Nieman LK, Sonino N, Vance ML, Giustina A \& Boscaro M. Diagnosis and complications of Cushing's syndrome: a consensus statement. Journal of Clinical Endocrinology and Metabolism 200380 5593-5602.

9 Yanovski JA, Cutler GB Jr, Chrousos GP \& Nieman LK. Corticotropin releasing hormone stimulation following low-dose dexamethasone administration. A new test to distinguish Cushing's syndrome from pseudo-Cushing's states. Journal of the American Medical Association $19932692232-2238$.

10 Yanovski JA, Cutler GB Jr, Chrousos GP \& Nieman LK. The dexamethasone-suppressed corticotropin-releasing hormone stimulation test differentiates mild Cushing's disease from normal physiology. Journal of Clinical Endocrinology and Metabolism 1998 83 348-352.

11 Martin NM, Dhillo WS, Banerjee A, Abdulali A, Jayasena CN, Donaldson M, Todd JF \& Meeran K. Comparison of the dexamethasone-suppressed corticotropin-releasing hormone test and low-dose dexamethasone suppression test in the diagnosis of Cushing's syndrome. Journal of Clinical Endocrinology and Metabolism $2006912582-2586$.

12 Wood PJ, Barth JH, Freedman DB, Perry L \& Sheridan B. Evidence for the low dose dexamethasone suppression test to screen for Cushing's syndrome-recommendations for a protocol for biochemistry laboratories. Annals of Clinical Biochemistry 199734 222-229. 
13 Pecori Giraldi F, Pivonello R, Ambrogio AG, De Martino MC, De Martin M, Scacchi M, Colao A, Toja PM, Lombardi G \& Cavagnini F. The dexamethasone-suppressed corticotropin-releasing hormone stimulation test and the desmopressin test to distinguish Cushing's syndrome from pseudo-Cushing's states. Clinical Endocrinology $200766251-257$.

14 Erickson D, Natt N, Nippoldt T, Young WF Jr, Carpenter PC, Petterson T \& Christianson T. Dexamethasone-suppressed corticotropin-releasing hormone stimulation test for diagnosis of mild hypercortisolism. Journal of Clinical Endocrinology and Metabolism 200792 2973-2977.

15 Gatta B, Chabre O, Cortet C, Martinie M, Corcuff JB, Roger P \& Tabarin A. Reevaluation of the combined dexamethasone suppression-corticotropin-releasing hormone test for differentiation of mild Cushing's disease from pseudo-Cushing's syndrome. Journal of Clinical Endocrinology and Metabolism 2007 92 4290-4293.

16 Reimondo G, Allasino B, Bovio S, Paccotti P, Angeli A \& Terzolo M. Evaluation of the effectiveness of midnight serum cortisol in the diagnostic procedures for Cushing's syndrome. European Journal of Endocrinology 2005153 803-809.
17 Newell-Price J, Bertagna X, Grossman AB \& Nieman LK. Cushing's syndrome. Lancet 2006367 1605-1617.

18 Nieman L. Editorial: the dexamethasone-suppressed corticotropinreleasing hormone test for the diagnosis of Cushing's syndrome: what have we learned in 14 years? Journal of Clinical Endocrinology and Metabolism 200792 2876-2878.

19 Terzolo M, Bovio S, Reimondo G, Pia A, Osella G, Borretta G \& Angeli A. Subclinical Cushing's syndrome in adrenal incidentalomas. Endocrinology and Metabolism Clinics of North America 2005 34 423-439.

20 Nieman LK, Biller BM, Findling JW, Newell-Price J, Savage MO, Stewart PM \& Montori VM. The diagnosis of Cushing's syndrome: an Endocrine Society Clinical Practice Guideline. Journal of Clinical Endocrinology and Metabolism 200893 1526-1540.

Received 7 August 2008

Accepted 11 August 2008 